\title{
Editorials
}

\section{Child maltreatment:}

\author{
time to rethink the role of general practice
}

Many children and young people do not receive the care, nurture, and protection that they need and deserve from adults in their household or wider community. They may suffer abuse or neglect, collectively termed maltreatment, or they are vulnerable due to their difficult circumstances at home.

Based on self- and parent-reports, between $4-10 \%$ of children and young people $<19$ years in the UK experience maltreatment each year, $>80 \%$ of which is attributable to parents or parentfigures. ${ }^{1,2}$ Far greater numbers of children can be considered 'vulnerable', living in very difficult household circumstances or with compromised parenting. Household surveys in England suggest more than one in five children live with an adult who misuses drugs or alcohol or who has a mental health problem. ${ }^{3}$

We recently published a report that challenged policy makers' perceptions about the role that general practice can play in the safeguarding of these children, young people, and their families. ${ }^{4}$ The findings from this overview of policy, practice, and research were positive: GPs in the UK already know about many maltreated and vulnerable children and young people, and we found examples of a range of GP responses to these children and their families. A better model of child safeguarding across general practice needs two things:

- policy makers and professionals to recognise and value the full breadth of GP responses to maltreated and vulnerable children; and

- health services to be organised in a way that facilitates these responses.

\section{IDENTIFICATION AND RECORDING}

While we do not have accurate estimates of the numbers of maltreated and vulnerable children identified by general practice each year in the UK, we do have evidence about how often these concerns are recorded. In a sample of almost 77000 children, $0.8 \%$ had a maltreatment-related Read code entered in their computerised medical record in a 12-month period, in 2010.4.5 This equates to approximately 90000 children in the whole of England. ${ }^{4}$ For an average general practice with around 1600 patients aged $<19$ years, that would be around 13 children. ${ }^{4}$ However, the number of children with active safeguarding concerns will be considerably higher. ${ }^{6}$ Although identification can be improved and is a necessary step in child safeguarding. GPs already know about a substantial number of maltreated and vulnerable children.

\section{RESPONDING: VALUING GPs' CORE SKILLS}

Some children and young people will have problems serious enough to warrant referral to children's social care, but many will not. It is now widely accepted that it is not feasible or appropriate to refer every concern; the numbers are simply too great. GPs have an important role in actively responding to this need that goes beyond referral.

Despite overt policy messages about shared safeguarding responsibility, in the 109 pieces of policy and practice-guidance that we reviewed as part of our report, there was a persistent subtext that saw GPs as 'sentinels', largely responsible for identifying and referring maltreated and vulnerable patients.

In contrast, evidence from qualitative studies tells us that a GP's role can be much broader. GPs can and do actively manage maltreated and vulnerable children by cultivating their role as 'trusted ally' and supporting children and their families, particularly their parents. ${ }^{4,7}$ This type of support requires year-on-year monitoring. It means helping and empowering parents to address lifestyle and health issues that affect their children, such as smoking, alcohol misuse, or physical or mental health problems. It recognises that:

- many maltreated and vulnerable children do not have an 'administratively competent carer';

- services might be off-putting and difficult to navigate for these families; and

- there may be unmet healthcare needs in both children and parents.
Active GP management aims to provide continuity and keep parents and young people coming back through the surgery doors. It includes being an advocate for these families to help them find their way through the health and social care systems. It involves writing to housing services, helping with benefit applications, rearranging hospital appointments, offering opportune care for children when they accompany adult patients to appointments, or by prioritising speedy access to care.

All these responses rely on GPs building and maintaining relationships with families and using this therapeutic relationship to engage parents and young people to better understand and address health needs in the whole family. They also rely on jointworking with others, especially health visitors.

These types of strategies can be described as 'direct responses' to children and families. They can occur before, after, or alongside referral to children's social care and participation in children protection procedures.

Direct responses to children and families are not new; they represent core skills of general practice. Patients who are elderly, who are receiving end-of-life care, who are chronically ill, or who have complex health needs, will need their GPs to monitor them, coach them about lifestyle and the way they manage their health, and to act as an advocate with other services on their behalf, all in the context of wider joint-working with professionals from other agencies.

Research is needed to establish whether direct responses improve things for children and families, how far they do so, and for which types of families. As in any robust evaluation, we must test for potential harms as well as benefits. However, such research is unlikely to be carried out until policy makers prioritise direct responses to children and families in general practice. Recognition of direct responses by policy 


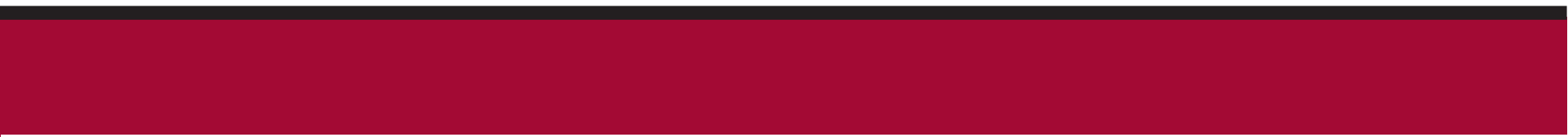

We challenge policy makers and professionals to rethink GPS' role in safeguarding and to recognise and value wider GP work in child safeguarding, examples of which do exist.

makers might give permission and incentive for commissioners to focus on systems to support joint-working as part of GPs' direct responses. This in turn may promote GPs' confidence in their ability to safeguard children, increase professional engagement, and reduce professional anxiety around child safeguarding in general practice.

Ultimately, we need randomised controlled trials to rigorously test the effectiveness of a 'best-practice' model of GP child safeguarding. On the way to establishing effectiveness, we need to think carefully about the way we organise services and the probable impact of this on GPs' ability to help maltreated and vulnerable children and their families.

\section{MODELS OF CARE THAT ENABLE}

The responses we describe rely heavily on GPs engaging families, building relationships with them, and cultivating a position as a 'trusted ally'. In short, they are rooted in a holistic approach that gives GPs time to listen and allows continuity of care. These are aspects of service that are difficult to deliver with the increasing demands on general practice, with changes to commissioning and within time-limited consultations. It is possible that longer consultations, a fast-track to appointments, and seeing the same doctor might be most appropriate for maltreated and vulnerable children and their families. Service and workforce organisation, pressure demands, and lack of resources in primary care undermine GPs' ability to be 'family doctors' and are also likely to be detrimental to their safeguarding role. ${ }^{4}$

Direct responses to children and families need to take place in the context of jointworking. It is likely to be helpful if there is an information loop between GPs, children's social care, education, and specialist healthcare services. Historically, GPs relied on health visitors to act as conduits of information from children's social care. ${ }^{4}$ However, health visitors are relocating away from GP practices; they increasingly have team workloads and carefully segmented service provision that may not allow them to make a primary care nursing response or offer continuity of care to children and families in the way that we describe for GPs. Safeguarding meetings within primary care teams have the potential to support information sharing between GPs and other agencies, to facilitate proactive monitoring of families, and promote joint decision making and peer supervision within this difficult work. 8,9 However, the evidence suggests that these meetings still have some way to go before they realise their potential. ${ }^{8}$

\section{CONCLUSION}

Safeguarding in general practice has the potential to use core 'family doctor' skills to meet the health needs (in the widest sense of the term) of maltreated and vulnerable children, young people, and their families and doing so in tandem with statutory child protection responses. We challenge policy makers and professionals to rethink GPs' role in safeguarding and to recognise and value wider GP work in child safeguarding, examples of which do exist. ${ }^{4}$ Models of care that promote continuity of care and a holistic approach are likely to facilitate effective GP responses to these children and their families.

\section{Jenny Woodman,}

Researcher, University College London, Institute of Child Health, London.

\section{Imran Rafi,}

GP and Chair of CIRC, Royal College of General Practitioners, London.

\section{Simon de Lusignan,}

GP, Professor of Primary Care and Clinical Informatics, University of Surrey; Director, RCGP Research and Surveillance Centre, Guildford.

\section{Provenance}

Commissioned; not externally peer reviewed.

\section{Competing interest}

This editorial is based on a collaborative report written by the current authors and other colleagues at the RCGP, NSPCC, UCL Institute of Child Health, and the University of Surrey:

http://www.nspcc.org.uk/Inform/research/findings/ gps-role-report wdf103317.pdf

\section{ADDRESS FOR CORRESPONDENCE}

Jenny Woodman

University College London, Population, Policy and Practice, 30 Guilford Street, London WC1N 1EH, UK

\section{E-mail: j.woodmanđucl.ac.uk}

\section{Acknowledgements}

We thank Dr Janice Allister. Professor Ruth Gilbert, and colleagues at the NSPCC with whom we wrote the report that forms the basis for this editorial. ${ }^{4}$

DOI: 10.3399/bjgp14X681265

\section{REFERENCES}

1. Radford L, Corral S, Bradley C, et al. Child abuse and neglect in the UK today. London: NSPCC Research Findings, 2011. http:// unw.nspcc.org.uk/Inform/research/findings/ child_abuse_neglect_research_wda84173.html laccessed 11 Aug 2014).

2. Gilbert R, Widom CS, Browne K, et al. Burden and consequences of child maltreatment in high-income countries. Lancet 2009; 373(9657): 68-81.

3. Manning V, Best DW, Faulkner N, Titherington $E$. New estimates of the number of children living with substance misusing parents: results from UK national household surveys. BMC Public Health 2009: 9: 377.

4. Woodman J, Woolley A, Gilbert R, et al. The $G P$ 's role in responding to child maltreatment: time for a rethink? An overview of policy, practice and research. London: NSPCC, 2014.

5. Woodman J, Freemantle N, Allister J, et al. Variation in recorded child maltreatment concerns in UK primary care records: a cohor study using The Health Improvement Network (THIN) database. PLoS One 2012; 7(11): 1-9.

6. Woodman J, Allister J, Rafi I, et al. A simple approach to improve recording of concerns about child maltreatment in primary care records: developing a quality improvement intervention. Br J Gen Pract 2012; DOI: 10.3399/ bjgp12X652346.

7. Batmanghelidjh C. Vulnerable children: creating a service fit for purpose. $\mathrm{Br} J \mathrm{Gen}$ Pract 2013; DOI: 10.3399/bjgp13X675214.

8. Woodman J, Gilbert R, Glaser D, et al. Vulnerable family meetings: a way of promoting team working in GPs' everyday responses to child maltreatment? Soc Sci2014; in press.

9. Brodie T, Knight S. The benefits of multidisciplinary safeguarding meetings. $\mathrm{Br} \mathrm{J}$ Gen Pract 2014; DOI: 10.3399/bjgp14X680701. 